\title{
Rheological Behaviour, Synthesis and Performance of Smart Thermal Barrier Coating Systems Based on Hollow Alumina
}

\author{
F. Pedraza*, B. Rannou, G. Boissonnet, B. Bouchaud, Z. Maache-Rezzoug \\ LaSIE, Université de La Rochelle-CNRS-UMR 7356, Pôle Sciences et Technologie, La Rochelle, France \\ Email: "fpedraza@univ-Ir.fr
}

Received 26 August 2015; accepted 10 December 2015; published 17 December 2015

\begin{abstract}
The stability of three water-based slurries containing different loads of Al microparticles was measured by laser scattering. The slurries displayed a Newtonian behaviour and the evolution of viscosity over nine days was found to be constant. Ground surfaces of nickel were also wetted similarly irrespective of the Al content in the slurries $(30,40$ or $50 \mathrm{wt} \%)$ thereby demonstrating that the 1/10 PVA/ $\mathrm{H}_{2} \mathrm{O}$ water based slurries are adequate for spraying. After deposition and annealing of the as-sprayed coatings, a thermal barrier coating system was formed with a top coat of hollow alumina spheres, an intermediate thermally grown oxide and a bottom aluminized bond coat. The coating system is shown to display very low thermal conductivity and remarkable oxidation resistance at high temperatures.
\end{abstract}

\section{Keywords}

Slurry, Viscosity, Wetting, Thermal Barrier Coating, Thermal Conductivity, Oxidation

\section{Introduction}

Thermal barrier coating systems in the high pressure aeronautical turbines are based on a (Ni, Pt) Al diffusion layer with a yttria-stabilized zirconia (YSZ) on top (e.g. [1]). However, many different coating techniques and steps are needed making them very costly. Therefore, their application is limited to other turbine components. In contrast, slurries composed of a suspension of insoluble particles in a liquid phase find a wide range of applications. For high temperature corrosion protection, plasma sprayed coatings [2] and simple [3], Si-doped [4] and Y-doped [5] diffusion aluminides were investigated. Full thermal barrier coatings from water-based slurries containing Al microparticles have been recently proposed onto different substrates using water-based [6] and organic-based slurries [7] and their mechanisms of formation discussed [8]. Among the water-soluble binders, polyvinyl alcohol (PVA) is preferred because of its adsorption onto aluminium (e.g. [9]). Yet the water/organic ratio is of prime importance to ensure appropriate wetting properties through adequate viscosity of the slurry (e.g. [10]) although our previous investigation demonstrated the physico-chemical stability of the slurry with

"Corresponding author.

How to cite this paper: Pedraza, F., Rannou, B., Boissonnet, G., Bouchaud, B. and Maache-Rezzoug, Z. (2015) Rheological Behaviour, Synthesis and Performance of Smart Thermal Barrier Coating Systems Based on Hollow Alumina. Journal of Materials Science and Chemical Engineering, 3, 17-22. http://dx.doi.org/10.4236/msce.2015.312004 
ageing time [11]. Reports on the correlations between the water-based slurry formulation and the characteristics of the spray dried granules have otherwise been well documented by Bertrand et al. [12] [13]. However, they referred to ceramic $\mathrm{Al}_{2} \mathrm{O}_{3}$ and $\mathrm{Y}_{2} \mathrm{O}_{3}-\mathrm{ZrO}_{2}$ particles and not to $\mathrm{Al}$ metal particles, which is the purpose of this communication. The synthesis, thermal conductivity and oxidation behaviour of these smart coatings is also described.

\section{Experimental Procedure}

1/10 PVA (Merck, CAS $\mathrm{n}^{\circ}$ : 9002-89-5) to ultra-pure water $\left(\mathrm{R}=18.2 \mathrm{M} \Omega \cdot \mathrm{cm}^{-1}\right) \mathrm{wt} \%$ ratios were employed as solution into which 30 (slurry A), 40 (slurry B) and 50 (slurry C) wt\% of Al microparticles (Sibthermochim, CAS n : 7429-90-5) were added. The slurries were shaken manually to obtain homogeneous suspensions and were stored in glass containers for up to 9 days after elaboration. Sedimentation measurements were performed by a multiple light scattering method using a Turbiscan lab expert apparatus (Formulaction, France) for which 3 $\mathrm{mL}$ of re-homogenized slurries were analyzed twice per minute every $40 \mu \mathrm{m}$, for one hour at $25^{\circ} \mathrm{C}$. Viscosity measurements were carried out in a TA Instrument AR 500 with a $2^{\circ}$ cone/plane geometry. The data acquisition was realized at $25^{\circ} \mathrm{C}$ over an applied shear rate from $0.1 \mathrm{~s}^{-1}$ to $2500 \mathrm{~s}^{-1}$ and the measured shear stress allowed to calculate the values of viscosity using the TA software Rheology Advantage Data Analysis. Wetting of the slurries onto SiC\#180 ground nickel substrates was determined with a See System (Masaryk University, Czech Republic) by recording the pictures with a CCD camera. Annealing of the coatings was undertaken in a thermogravimetric analyzer (TGA) apparatus (Setaram TGA-92) as described in [8]. Thermal conductivity was calculated measured by the laser flash method in a LFA- $1600^{\circ} \mathrm{C}$ (LINSEIS) and isothermal oxidation was performed between $900^{\circ} \mathrm{C}$ and $1100^{\circ} \mathrm{C}$ for $100 \mathrm{~h}$ in air (Setaram TGA-92). Characterization was carried out by scanning electron microscopy (SEM) with a coupled energy dispersive spectrometer (EDS) and by X-ray diffraction, XRD ( $\mathrm{Cu} \mathrm{k}$ r radiation).

\section{Results and Discussion}

\subsection{Slurry Characterization}

Figure 1 depicts the evolution of the destabilization measurement of slurry A (30 wt\% Al) on the as-prepared condition (i.e. un-aged). Similar curves were also obtained for slurries B (40 wt $\% \mathrm{Al}$ ) and C (50 wt\% Al). The evolution of the backscattered signal translates the clarification/sedimentation front with respect the position in the crucible. The decrease of the backscattered signal with time is indicative of a lower concentration of $\mathrm{Al}$ particles (clarification) at the top of the crucible whereas the opposite (sedimentation) occurs at the bottom. The inflection points appearing on the sedimentation front highlighted by the red darts of Figure $\mathbf{1}$ are ascribed to the different sizes of the particles [2 - $10 \mu \mathrm{m}$ ] in the dispersion [14], whereby coarser particles sediment faster than the smallest ones if one assumes a Newtonian fluid [15].

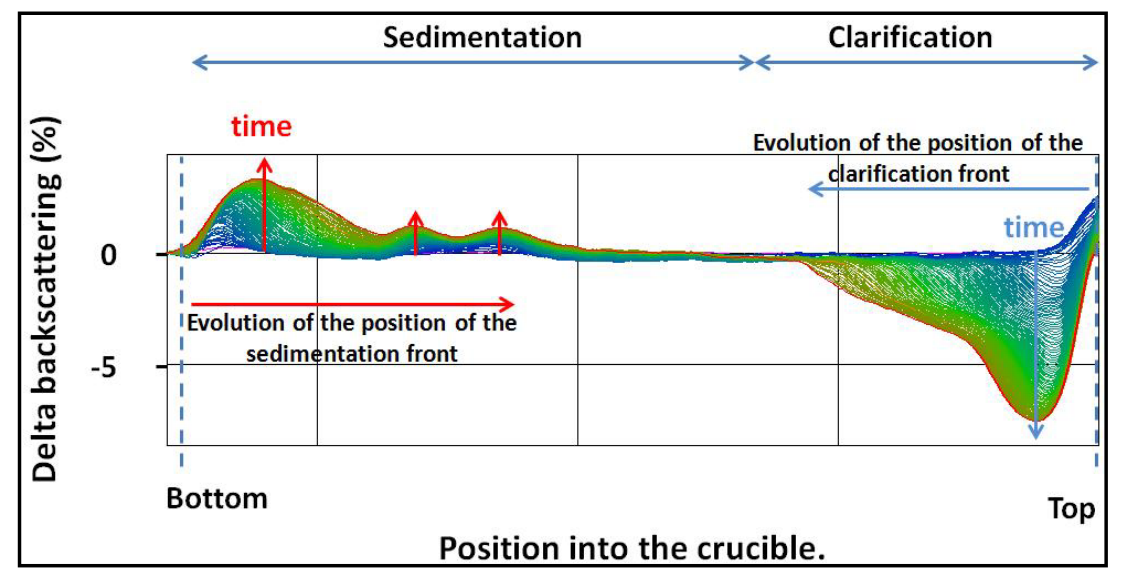

Figure 1. Evolution of the backscattered data with respect the position in the crucible and the associated domains of clarification (top) and sedimentation (bottom) of slurry A in the as-prepared condition. NB: each monochromatic line corresponds to an average measurement taken every minute for up to $1 \mathrm{~h}$. 
The shear stress measured against the applied shear rate for the different slurries resulted in linear curves of which the slope allowed to calculate the viscosity $(\eta)$ using the Newtonian fluid description [14]. In case of physicochemical changes in the solvent, better monitoring of the slurries with ageing time is usually achieved by measuring the relative viscosity $\left(\eta_{\mathrm{r}}=\eta_{\text {fluid }} / \eta_{\text {solven }} \mathrm{t}\right)$ in case physicochemical changes occurred in the solvent. However, the viscosity measurements of solvent ranged between 0.029 and $0.028 \mathrm{~Pa} \cdot \mathrm{s}^{-1}$ over the nine days (Figure 2) and thus highlight the stability of the $1 \mathrm{PVA} / 10 \mathrm{H}_{2} \mathrm{O}$ mixtures. In agreement with many other works in which modified Stokes equations were introduced to consider the shape and density of the load (e.g. [16][18]), the greater the $\mathrm{Al}$ content, the higher the viscosity value . However, and irrespective of the $\mathrm{Al}$ content, the viscosity is slightly lowered between the day of elaboration and two days afterwards and subsequently stabilizes up to the end of the ageing test. Some "crusting" phenomenon was observed though for slurry C (50 wt\% Al) leading to a solidification of the slurry for the low shear rates due to the evaporation of the free-water. In spite of this, a Newtonian behavior is derived, which is in contrast with the non-Newtonian behavior reported in $\mathrm{Al}$ microsized $(1.4 \mu \mathrm{m})$ suspensions of hydroxyl-terminated polybutadiene (HTPB) under dynamic tests [19] but in agreement with the Newtonian behavior observed in nano-sized paraffin oil suspensions [20]. It is therefore believed that the slurry ratios of water, PVA and Al microparticles studied here allow the initial dissolution of PVA in water [21] and the bonding of PVA to the Al microparticles [9], irrespective of the Al load. Therefore, the suspension is stable up to nine days from the sedimentation and viscosity considerations and the SiC\#180 polished nickel substrates are thus similarly wetted with all three slurries (Figure 3).

\subsection{Coating Deposition and Performance}

Annealing of the sprayed coatings in a single step process at $700^{\circ} \mathrm{C} / 2 \mathrm{~h}+1100^{\circ} \mathrm{C} / 2 \mathrm{~h}$ under flowing $\operatorname{Ar}(\mathrm{g})$ resulted in the coating structure illustrated in Figure 4(a). The coating system consists of a top coat of hollow alumina spheres, a thermally grown oxide (TGO) based on alumina and a NiAl bond coat diffused into the nick el substrate. The mechanisms of formation were thoroughly explained in [8]. They appear from supply of $\mathrm{Al}$ to the nickel substrate while the shells of the $\mathrm{Al}$ microspheres at the top crack and oxidize so as to form hollow and broken spheres with a $\alpha-\mathrm{Al}_{2} \mathrm{O}_{3}$ crust. The reaction pathway is very fast due to the great exothermal reactions between $\mathrm{Al}$ and $\mathrm{Ni}$ [22]. A $40 \mu \mathrm{m}$ thick top coat of hollow spheres exhibit similar thermal conductivity values than a conventional $400 \mu \mathrm{m}$-thick YSZ coating deposited by air plasma spray (Figure 4(b)).

The oxidation kinetics between $900^{\circ} \mathrm{C}$ and $1100^{\circ} \mathrm{C}$ displayed in Figure 5(a) are also shown to be equivalent to a bulk $\beta$ - $\mathrm{NiAl}$ [23] when the top coat is removed because of the remnants of metallic $\mathrm{Al}$ in the spheres [24]. Protection is provided by the growth of the alumina TGO. A mixed spinel $\mathrm{NiAl}_{2} \mathrm{O}_{4}$ oxide forms though at $1100^{\circ} \mathrm{C}$ (Figure 5(b)) due to fast outward diffusion of Ni [25].

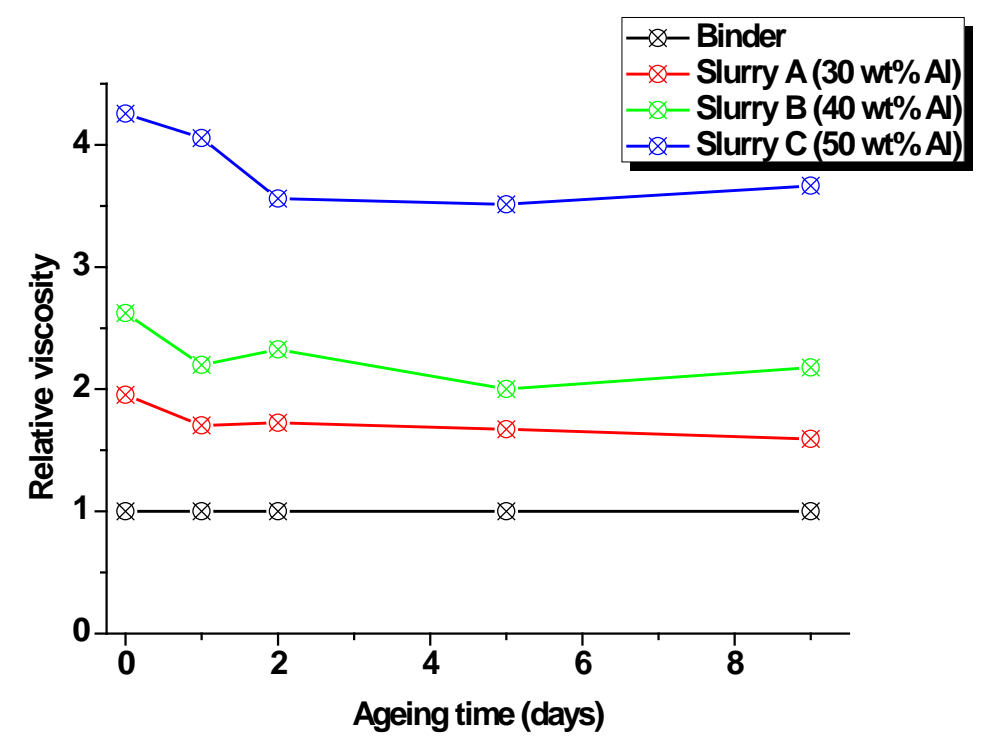

Figure 2. Evolution of the relative viscosity with ageing time for the different water-based slurries. 


\begin{tabular}{l|lll}
\hline Drying time & Slurry A & Slurry B & Slurry C \\
\hline $30 \mathrm{sec}$ & & & \\
\hline
\end{tabular}

Figure 3. Drops of the different slurries deposited by pipette onto ground nickel substrates after $30 \mathrm{~s}$ and 5 min of drying at room temperature in open air.

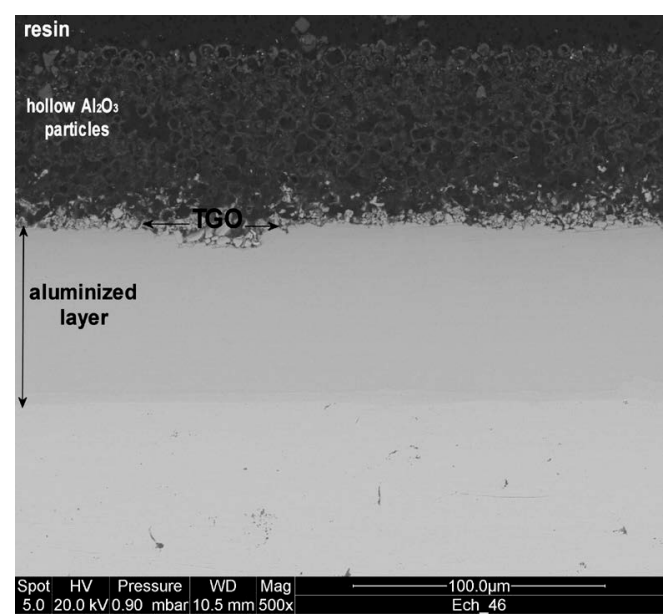

(a)

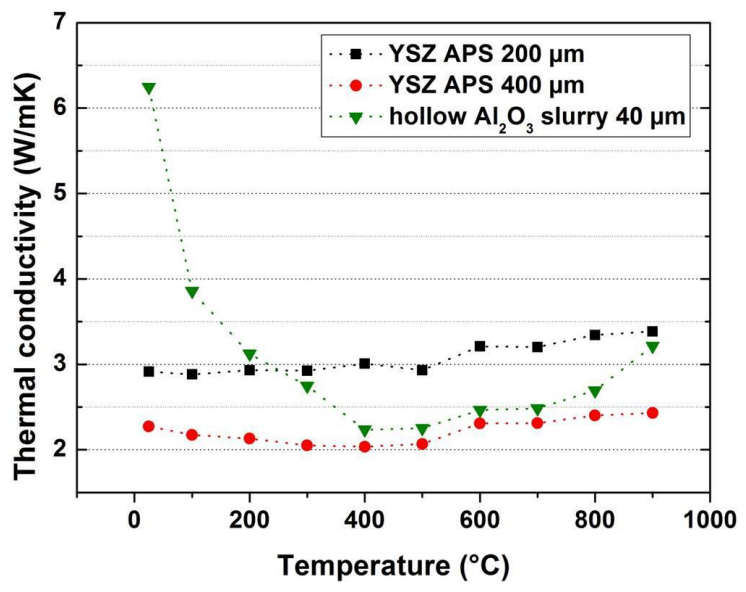

(b)

Figure 4. (a) SEM microstructure of a thermal barrier coating system sintered from a water based slurry onto a pure nickel substrate; (b) Thermal conductivity of the top coat of the slurry compared to conventional YSZ coatings of different thickness.

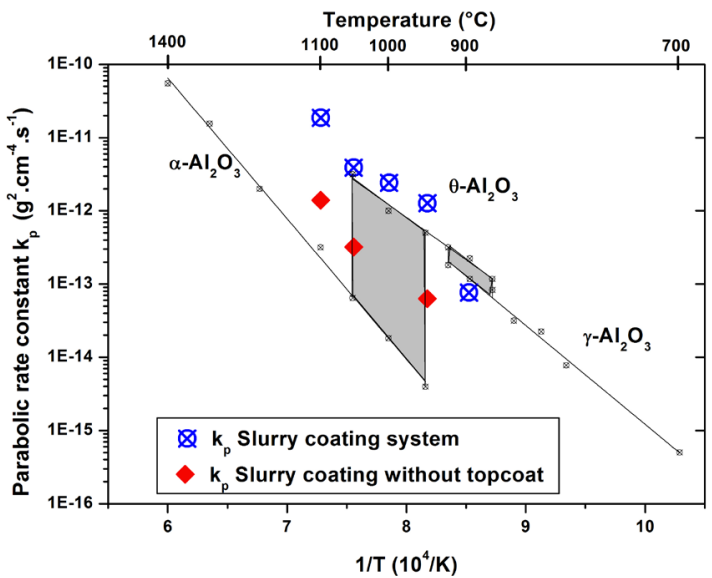

(a)

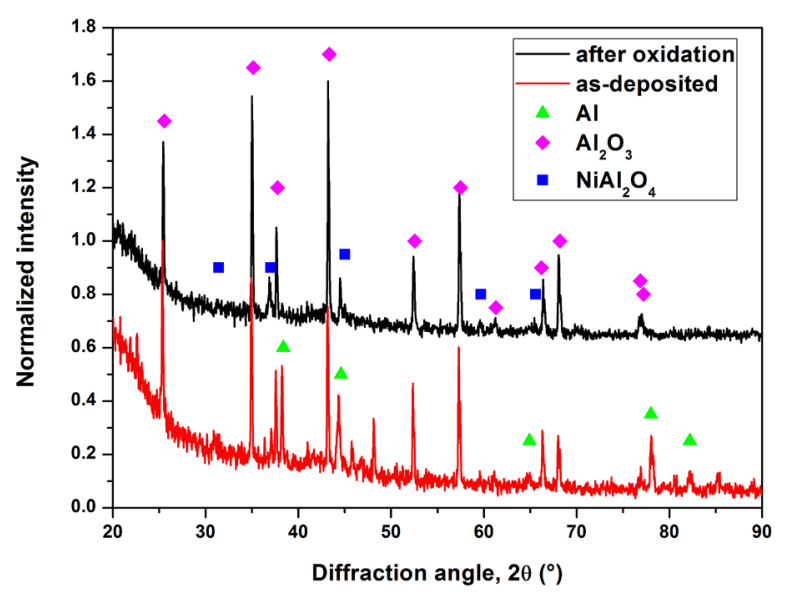

(b)

Figure 5. (a) Relationship between the parabolic rate constants and oxidation temperature of the slurry coatings (full and with the top coat removed) after $100 \mathrm{~h}$ of isothermal oxidation in synthetic air; (b) XRD patterns of the coatings before and after oxidation at $1100^{\circ} \mathrm{C}$ for $100 \mathrm{~h}$ in air. Note the disappearance of the Al metallic peaks and the growth of the mixed spinel $\mathrm{NiAl}_{2} \mathrm{O}_{4}$ oxide. 


\section{Acknowledgements}

Part of this study was supported under the programme PARTICOAT FP7-NMP-LARGE-211329 (2008-2012) funded by the European Union.

\section{References}

[1] Nicholls, J.R. (2003) Advances in Coating Design for High-Performance Gas Turbines. MRS Bull., 28, 659-670. http://dx.doi.org/10.1557/mrs2003.194

[2] Schrijnemakers, A., André, S., Lumay, G., Vandewalle, N., Boschini, F., Cloots, R. and Vertruyen, B. (2009) Mullite Coatings on Ceramic Substrates: Stabilisation of $\mathrm{Al}_{2} \mathrm{O}_{3}-\mathrm{SiO}_{2}$ Suspensions for Spray Drying of Composite Granules Suitable for Reactive Plasma Spraying. J. European Ceram. Soc., 29, 2169-2175. http://dx.doi.org/10.1016/j.jeurceramsoc.2009.01.031

[3] Rasmussen, A.J., Agüero, A., Gutiérrez, M. and Östergaard, M.L.J. (2008) Microstructures of Thin and Thick Slurry Aluminide Coatings on Inconel 690. Surf. Coating Technol., 202, 1479-1485. http://dx.doi.org/10.1016/j.surfcoat.2007.06.056

[4] Young, S.G. and Deadmore, D.L. (1979) An Experimental Low Cost Silicon Slurry/Aluminide Coating for High Temperature Coating for Superalloys. NASA Technical Memorandum, 79178, 1-10.

[5] Wang, F.H., Lou, H.Y., Bai, L.X. and Wu, W.T. (1989) Hot Corrosion of Yttrium-Modified Aluminide Coatings. Mater. Sci. Eng. A, 120-121, 387-389. http://dx.doi.org/10.1016/0921-5093(89)90792-2

[6] Montero, X., Galetz, M. and Schütze, M. (2011) A Single Step Process to Form In-Situ an Alumina Foam/Aluminide TBC System for Alloys in Extreme Environments at High Temperatures. Surf. Coating. Technol., 206, 1586-1594. http://dx.doi.org/10.1016/j.surfcoat.2011.05.052

[7] Kolarik, V., Juez-Lorenzo, M., Anchústegui, M. and Fietzek, H. (2008) Multifunction High Temperature Coating System Based on Aluminium Particle Technology. Mater. Sci. Forum, 595-598, 769-777. http://dx.doi.org/10.4028/www.scientific.net/MSF.595-598.769

[8] Pedraza, F., Mollard, M., Rannou, B., Balmain, J., Bouchaud, B. and Bonnet, G. (2012) Potential Thermal Barrier Coating Systems from Al Microparticles, Mechanisms of Coating Formation and Oxidation Resistance on Pure Nickel. Mater. Chem. Phys., 134, 700-705. http://dx.doi.org/10.1016/j.matchemphys.2012.03.053

[9] Umoren, S.A., Ogbobe, O., Okafor, P.C. and Ebenso, E.E. (2007) Polyethylene Glycol and Polyvinyl Alcohol as Corrosion Inhibitors for Aluminium in Acidic Medium. J. Appl. Polymer Sci., 105, 3363-3370. http://dx.doi.org/10.1002/app.26530

[10] Ananthakumar, S., Menon, A.R.R., Prabhakaran, K. and Warrier, K.G.K. (2001) Rheology and Packing Characteristics of Alumina Extrusion Using Boehmite Gel as a Binder. Ceram. Int., 27, 231-237. http://dx.doi.org/10.1016/S0272-8842(00)00070-5

[11] Rannou, B., Velasco, F., Guzmán, S., Kolarik, V. and Pedraza, F. (2012) Aging and Thermal Behavior of a PVA/Al Microspheres Slurry for Aluminizing Purposes. Mater. Chem. Phys., 134, 360-365. http://dx.doi.org/10.1016/j.matchemphys.2012.03.002

[12] Bertrand, G., Filiatre, C., Mahdjouba, H., Foissy, A. and Coddet, C. (2003) Influence of Slurry Characteristics on the Morphology of Spray-Dried Alumina Powders. J. European Ceram. Soc., 23, 263-271. http://dx.doi.org/10.1016/S0955-2219(02)00171-1

[13] Bertrand, G., Roy, P., Filiatre, C. and Coddet, C. (2005) Spray-Dried Ceramic Powders: A Quantitative Correlation between Slurry Characteristics and Shapes of the Granules. Chem. Eng. Sci., 60, 95-102. http://dx.doi.org/10.1016/j.ces.2004.04.042

[14] Ivanov, Y.F., Osmonoliev, M.N., Sedoi, V.S., Arkhipov, V.A., Bondarchuk, S.S., Vorozhtsov, A.B., Korotkikh, A.G. and Kuznetsov, V.T. (2003) Productions of Ultra-Fine Powders and Their Use in High Energetic Compositions. Propell. Explos. Pyrot, 28, 319-333. http://dx.doi.org/10.1002/prep.200300019

[15] Barnes, H.A. (2000) A Handbook of Elementary Rheology. Institute of Non-Newtonian Fluid Mechanics, University of Wales, Aberystwyth.

[16] Mooney, M. (1951) The Viscosity of a Concentrated Suspension of Spherical Particles. J. Colloid Science, 6, 162-170. http://dx.doi.org/10.1016/0095-8522(51)90036-0

[17] Marrucci, G. and Denn, M.M. (1985) On the Viscosity of a Concentrated Suspension of Solid Spheres. Rheologica Acta, 24, 317-320. http://dx.doi.org/10.1007/BF01332611

[18] Toda, K. and Furuse, H. (2006) Extension of Einstein's Viscosity Equation to That for Concentrated Dispersions of Solutes and Particles. J. Biosci. Bioeng., 102, 524-528. http://dx.doi.org/10.1263/jbb.102.524 
[19] Mitsumata, T., Hachiya, T. and Nitta, K. (2008) Nonlinear Viscoelasticity, Percolation and Particles Dispersibility of PVA-Aluminum Hydroxide Composite Gels. European Polymer J., 44, 2574-2580. http://dx.doi.org/10.1016/j.eurpolymj.2008.06.009

[20] Teipel, U. and Förther-Barth, U. (2001) Rheology of Nano-Scale Aluminum Suspensions. Propell. Explos. Pyrot., 26, 268-272. http://dx.doi.org/10.1002/1521-4087(200112)26:6<268::AID-PREP268>3.0.CO;2-L

[21] LeBeau, J.M. and Boonyongmaneerat, Y. (2007) Comparison Study of Aqueous Binder Systems for Slurry-Based Processing. Mater. Sci. Eng. A, 458, 17-24. http://dx.doi.org/10.1016/j.msea.2007.01.112

[22] Galetz, M.C., Montero, X., Mollard, M., Günthner, M., Pedraza, F. and Schütze, M. (2014) The Role of Combustion Synthesis in the Formation of Slurry Aluminization. Intermetallics, 44, 8-17. http://dx.doi.org/10.1016/j.intermet.2013.08.002

[23] Brumm, M.W. and Grabke, H.J. (1992) The Oxidation Behaviour of NiAl-I. Phase Transformations in the Alumina Scale during Oxidation of NiAl and NiAl-Cr Alloys. Corros. Sci., 33, 1677-1690. http://dx.doi.org/10.1016/0010-938X(92)90002-K

[24] Mollard, M., Rannou, B., Bouchaud, B., Balmain, J., Bonnet, G. and Pedraza, F. (2013) Comparative Degradation of Nickel Aluminized by Slurry and by Pack Cementation under Isothermal Conditions. Corros. Sci., 66, 118-124. http://dx.doi.org/10.1016/j.corsci.2012.09.009

[25] Peraldi, R., Monceau, D. and Pieraggi, B. (2002) Correlations between Growth Kinetics and Microstructure for Scales Formed by High-Temperature Oxidation of Pure Nickel. I. Morphologies and Microstructures. Oxid. Met., 58, 249273. http://dx.doi.org/10.1023/A:1020170320020 